\title{
Fenestration closure with Amplatzer Duct Occluder II in patients after total cavo-pulmonary connection
}

Sebastian Góreczny ${ }^{1}$, Paweł Dryżek ${ }^{1}$, Gareth J. Morgan², Anna Mazurek-Kula ${ }^{1}$, Jacek J. Moll ${ }^{3}$, Jadwiga A. Moll' ${ }^{1}$, Shakeel Qureshi², Tomasz Moszura ${ }^{1}$

\author{
${ }^{1}$ Department of Cardiology, Polish Mother's Memorial Hospital, Research Institute, \\ Lodz, Poland \\ 2Department of Congenital Heart Disease, Evelina London Children's Hospital, \\ Guy's and St Thomas' NHS Foundation Trust, London, United Kingdom \\ ${ }^{3}$ Department of Cardiac Surgery, Polish Mother's Memorial Hospital, Research \\ Institute, Lodz, Poland
}

Submitted: 4 March 2015

Accepted: 16 March 2015

Arch Med Sci 2017; 13, 2: 337-345

DOI: https://doi.org/10.5114/aoms.2016.61836

Copyright $\odot 2016$ Termedia \& Banach

\section{Abstract}

Introduction: Creation of a fenestration during completion of a total cavopulmonary connection (TCPC) has been associated with a reduction in early mortality and morbidity. However, the long-term benefits are negated by an associated limitation in exercise tolerance and the potential risks of thrombo-embolic complications. We sought to describe the safety and efficacy of an Amplatzer Duct Occluder II (ADO II) for transcatheter fenestration closure following TCPC.

Material and methods: Between January 2000 and July 2014, 102 patients underwent percutaneous closure of extra-cardiac TCPC fenestrations with a range of devices. Patients in whom fenestration closure was performed with an ADO II and who had at least 6 months of follow-up were included in this study.

Results: Forty-seven patients had successful fenestration occlusion with an ADO II. The mean oxygen saturation and mean systemic venous pressures increased from $84.8 \pm 6.1 \%$ before to $97.6 \pm 2.9 \%(p<0.001)$ after and from $14.2 \pm 2.15 \mathrm{~mm} \mathrm{Hg}$ before to $15.6 \pm 2.2 \mathrm{~mm} \mathrm{Hg}$ after closure $(p<0.001)$. Eight patients developed heart failure symptoms, managed by optimization of medical therapy, with 1 patient requiring device removal to reopen the fenestration. Color Doppler transthoracic echocardiography demonstrated residual flow across the device in 18 (38\%), 10 (22\%), $5(11 \%)$ and $4(9 \%)$ patients before discharge, at 1 and 6 months, and at the latest outpatient visit, respectively.

Conclusions: The ADO II can be safely and effectively used to close fenestrations in extra-cardiac type Fontan completions. Many of the design features of this device confer potential benefit in this population.

Key words: congenital heart disease, new devices, percutaneous intervention.

\section{Introduction}

Creation of a fenestration during completion of a total cavo-pulmonary connection (TCPC) has been associated with a reduction in early mortality and morbidity, especially in patients with various risk factors [1-4]. The mechanism for this reduction is likely to be related to aug-

\author{
Corresponding author: \\ Sebastian Góreczny MD, PhD \\ Department of Cardiology \\ Polish Mother's \\ Memorial Hospital \\ Research Institute \\ Rzgowska 281/289 \\ 93-338 Lodz, Poland \\ Phone: +48 422711478 \\ E-mail: sebastiangoreczny@ \\ yahoo.pl
}


mentation of ventricular preload and reduction in systemic venous pressure [3-6]. The long-term benefits of a right-to-left shunt facilitated by the fenestration are negated by an associated limitation in exercise tolerance and the potential risks of thrombo-embolic complications [7-10]. A number of different devices have been used to close fenestrations including coils, plugs, double-disc occluders and covered stents [11-19].

The Amplatzer Duct Occluder II (ADO II; St. Jude Medical, St. Paul, Minnesota) was designed for transcatheter patent arterial duct closure [20-22].

Table I. Diagnosis, medications and echocardiography data prior to fenestration closure

\begin{tabular}{|c|c|}
\hline Diagnosis & Value \\
\hline Hypoplastic left heart syndrome & $37(79 \%)$ \\
\hline Mitral atresia & $3(6 \%)$ \\
\hline Double inlet left ventricle & $3(6 \%)$ \\
\hline Tricuspid atresia & $2(4 \%)$ \\
\hline Pulmonary atresia & $1(2 \%)$ \\
\hline Common ventricle & $1(2 \%)$ \\
\hline \multicolumn{2}{|l|}{ Systemic ventricle: } \\
\hline Right & $40(85 \%)$ \\
\hline Left & $6(13 \%)$ \\
\hline Indeterminate & $1(2 \%)$ \\
\hline \multicolumn{2}{|l|}{ Medication: } \\
\hline Aspirin & $45(96 \%)$ \\
\hline Warfarin & $2(4 \%)$ \\
\hline ACEI & $27(57 \%)$ \\
\hline Diuretics & $36(77 \%)$ \\
\hline Digoxin & $13(28 \%)$ \\
\hline Sildenafil & $21(45 \%)$ \\
\hline \multicolumn{2}{|l|}{ Echocardiograph parameters: } \\
\hline \multicolumn{2}{|c|}{ Atrio-ventricular valve regurgitation: } \\
\hline None & $6(13 \%)$ \\
\hline Trivial & $30(64 \%)$ \\
\hline Mild & $11(23 \%)$ \\
\hline \multicolumn{2}{|l|}{ Single ventricle function: } \\
\hline Good & $40(85 \%)$ \\
\hline Mild impairment & $6(13 \%)$ \\
\hline Moderate impairment & $1(2 \%)$ \\
\hline Fenestration size [mm] & $5.10 \pm 1.2$ \\
\hline Fenestration gradient [ $\mathrm{mm} \mathrm{Hg}$ ] & $10.1 \pm 2.1$ \\
\hline
\end{tabular}

Subsequently, it has been used in various congenital and acquired defects including ventricular septal defects, coronary arterial fistulas, aorto-pulmonary windows and paravalvular leaks [23-28]. This is the largest published report evaluating efficacy and safety of the ADO II for closure of fenestrations in patients after extra-cardiac TCPC.

\section{Material and methods}

\section{Study population}

Between January 2000 and July 2014, 102 patients after TCPC underwent percutaneous fenestration closure with a range of devices. The ADO II device was used in 53 cases, 47 of whom have achieved at least 6 months of post-procedure active follow-up. The local medical ethics committee approved the study, and individual patient consent was waived due to the retrospective nature of the research. The medical notes, catheterization reports and outpatient clinic notes were reviewed as the primary data sources. Patients' demographic data, medications, oxygen saturations and echocardiography results before and after the intervention were recorded. Complications including vascular trauma and new heart failure symptoms (hepatomegaly, ascites, peripheral edema, low diuresis, tachycardia) after fenestration occlusion were noted as well. The indication for intervention was a low resting oxygen saturation $(77.1 \pm 5.9 \%)$ with a patent fenestration confirmed on transthoracic echocardiography (TTE). All of the patients had some degree of subjective exercise limitation, but this was not formally assessed prior to closure.

The diagnoses, medications and echocardiographic parameters are summarized in Table I. The intervention was performed at a median of 12.6 months (range: 0.1-51 months) after the TCPC procedure with the median age and weight of 6.1 years (range: $3.9-10.6$ years) and $18 \mathrm{~kg}$ (range: $14.4-35 \mathrm{~kg}$ ), respectively.

\section{Fenestrated TCPC operation and fenestration closure}

The fenestrated TCPC operation was performed on a beating heart unless other concomitant surgical intervention was required. An extracardiac conduit technique was used in all cases. Prior to 2011 this was performed using aortic or pulmonary homografts, and since 2011 Gore-Tex tubes have been used. Fenestrations were only placed in those patients felt to be at higher risk of early post-operative morbidity. They were created using a punch biopsy tool through the corresponding surfaces of the conduit and the wall of the atrium, and then stabilized using direct suture fixation. The size of the fenestration was 4 or $5 \mathrm{~mm}$ in most cases. 
Fenestration closure was performed under general anesthesia with mechanical ventilation with $40 \%$ oxygen. Vessel access was achieved in the standard fashion, preferably through the right femoral vein, and $100 \mathrm{lU} / \mathrm{kg}$ of heparin was administered along with antibiotic prophylaxis. After hemodynamic evaluation of the Fontan pathway, angiography was performed in order to demonstrate the position, morphology and size of the fenestration. Early in the series, angiography was performed in a right anterior oblique (30-50 $)$ projection, whilst in the more recent patients, rotational angiography with 3D reconstruction (3DRA) was used for the assessment. The fenestration was crossed with a guidewire, and a $4 \mathrm{Fr}$ balloon wedge catheter was used to perform a test occlusion for $10 \mathrm{~min}$, whilst systemic venous pressure, arterial pressure and arterial saturations were monitored. A systemic venous pressure above $18 \mathrm{~mm} \mathrm{Hg}$ or an increase after balloon occlusion of more than $5 \mathrm{~mm} \mathrm{Hg}$ precluded device occlusion. The delivery catheter appropriate for the ADO II was introduced across the communication and the occluder was deployed under fluoroscopic guidance. After confirming stability, the device was released. Repeat hemodynamic measurements and angiography were performed. The intervention was judged successful if the device conformed appropriately and check angiography revealed no more than mild residual flow across the fenestration. All the patients received a single daily oral dose of aspirin (3-5 mg/kg up to a maximum of $75 \mathrm{mg}$ ) as ongoing therapy unless they were already on warfarin. A TTE was performed in all patients on the day after fenestration closure. Follow-up visits including physical examination and TTE were scheduled at 1 and 6 months after fenestration closure and 6-12 months thereafter.

\section{Statistical analysis}

All data analyses were performed using GraphPad InStat software (GraphPad Inc). Data are presented as frequency, median with range, or mean \pm standard deviation, as appropriate. Continuous variables were analyzed using a Mann-Whitney

Table II. Type of additional interventions $(N=22)$

\begin{tabular}{|ll|}
\hline Additional interventions & $N$ \\
\hline Existing pulmonary artery stent redilation & 8 \\
\hline Veno-venous collateral closure & 6 \\
\hline Pulmonary artery stent implantation & 5 \\
\hline Pulmonary arterio-venous collateral closure & 1 \\
\hline Extracardiac tunnel balloon dilatation & 1 \\
\hline Recoarctation balloon dilatation & 1 \\
\hline
\end{tabular}

and Student $t$ test. Dichotomous and categorical variables were compared with Fisher exact and $\chi^{2}$ tests. Paired data were examined using the paired two-tailed $t$ test. The level of statistical significance was set at $p \leq 0.05$.

\section{Results}

Fifty-three patients underwent fenestration closure with the ADO II device. Of these, 47 have completed at least 6 months of follow-up, meeting the inclusion criteria for this study. The mean oxygen saturation in room air, measured by finger-tip pulse oximetry, before the intervention was 77.1 $\pm 5.9 \%$. On angiography a single surgical fenestration was observed in 40 patients. Seven (17.5\%) patients had additional sources of right-to-left shunt: veno-venous collaterals in 6 patients and a pulmonary arterio-venous fistula in 1 patient.

Twenty (42\%) patients underwent 22 additional interventions during the index catheterization (Table II). Eighteen patients had 2 interventions and 2 patients had 3 interventions. Fenestration closure was performed after all the other interventions.

The mean diameter of the fenestration on angiography was $5.1 \pm 0.9 \mathrm{~mm}$, and the corresponding sizes of ADO II implanted are described in Table III. The mean oxygen saturation increased from 84.8 $\pm 6.1 \%$ before to $97.6 \pm 2.9 \%$ after the occlusion $(p<0.001)$. The mean systemic venous pressure increased from $14.2 \pm 2.15 \mathrm{~mm} \mathrm{Hg}$ before to 15.6 $\pm 2.2 \mathrm{~mm} \mathrm{Hg}$ after the occlusion $(p<0.001)$. Angiography immediately after device closure demonstrated residual flow in 43 (91.5\%) patients. In 4 patients, there was no immediate residual shunt across the device (Figure 1).

The mean radiation dose and fluoroscopy times were $279.25 \pm 188.7 \mathrm{mGy}$ and $13.8 \pm 7.8 \mathrm{~min}$ respectively.

The vast majority $(45 / 47)$ of procedures were technically uncomplicated, but the device needed to be revised in two patients during the index procedure. Angiography in one patient showed a $6.5 \mathrm{~mm}$ fenestration with satisfactory hemodynamics during balloon test occlusion. A $6 / 6 \mathrm{~mm}$ ADO II was implanted into the communication,

Table III. Size of occluder device $(N=47)$

\begin{tabular}{|lc|}
\hline Size of implanted ADO II [mm] & Value \\
\hline $3 / 4$ & $3(6 \%)$ \\
\hline $4 / 4$ & $5(11 \%)$ \\
\hline $5 / 4$ & $26(55 \%)$ \\
\hline $6 / 4$ & $13(28 \%)$ \\
\hline
\end{tabular}

ADO II - Amplatzer Duct Occluder II. The first number indicates diameter of the waist and the second length of the device. 


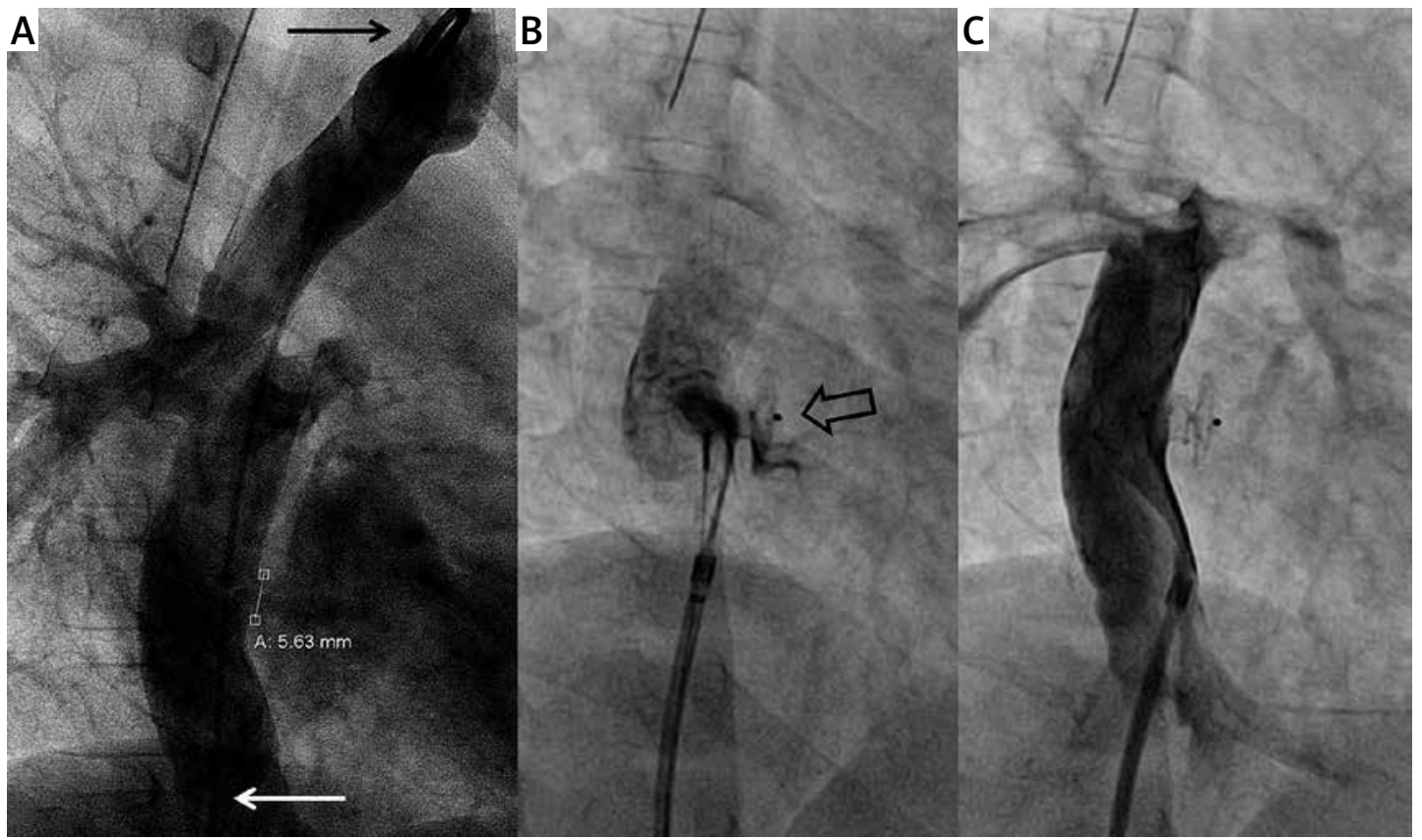

Figure 1. Fenestration closure with ADO II in a HLHS patient. A - Initial rotational angiogram with simultaneous contrast injection in the innominate vein (black arrow) and inferior vena cava (white arrow) shows the fenestration. B - Hand contrast injection prior to release of the ADO II device (empty black arrow) shows trivial residual flow at the bottom edge of the occluder. C - Final angiography through the delivery sheath shows complete occlusion of the fenestration with both discs of the device well aligned to the walls of the tunnel and the right atrium ADO II - Amplatzer Duct Occluder II, HLHS - hypoplastic left heart syndrome.

but angiography after release revealed significant residual flow, judged to be related to the distance between the two discs of the ADO II. The occluder was easily removed with a $10 \mathrm{~mm}$ Amplatz gooseneck snare (St. Jude Medical, St. Paul, Minnesota) and replaced with a shorter $6 / 4 \mathrm{~mm}$ device. Final angiography showed the occluder in a good position with mild residual flow.

Another patient with a $5 \mathrm{~mm}$ fenestration had a 5/4 mm device implanted. Subsequent angiography revealed significant residual flow through the lower part of the device due to improper orientation of the right-sided disc. The occluder was easily manipulated and repositioned with a $10 \mathrm{~mm}$ goose-neck snare, resulting in only mild residual flow.

\section{Outcomes}

The mean room air oxygen saturation measured by finger-tip pulse oximetry on the day before the intervention and on the following day after fenestration closure increased from $77.1 \pm 5.9 \%$ to 94.4 $\pm 2.2 \%$ ( $p<0.0001$ ). Color Doppler TTE performed on the next day showed trivial or mild residual flow in 18 (38\%) patients. One patient developed a small arterio-venous fistula, which was successfully managed by pressure dressing.

Eight patients developed symptoms and signs of heart failure after fenestration closure. Initial management was by optimizing preexisting medi- cal therapy and addition of sildenafil. One patient did not improve with medical therapy, requiring reopening of the fenestration. Prior to fenestration closure, this 7-year-old patient had oxygen saturations of $75 \%$ and significantly reduced exercise capacity. A TTE showed moderate impairment of the systemic ventricular function, mild tricuspid valve regurgitation and a $6 \mathrm{~mm}$ fenestration with a pulsed wave Doppler derived gradient of $7 \mathrm{~mm} \mathrm{Hg}$. During catheterization a previously implanted stent in the left pulmonary artery was redilated, before test occlusion of the fenestration resulted in a saturation increase from $80 \%$ to $98 \%$ and systemic venous pressure increase from 16 to $19 \mathrm{~mm} \mathrm{Hg}$. His fenestration was technically successfully closed with a 6/4 mm ADO II. Despite optimization of diuretics and commencing sildenafil, his heart failure symptoms worsened and he developed bilateral pleural effusions and ascites. He further deteriorated, and required inotropic support. On the fifth day after fenestration closure, the occluder was removed in the catheter laboratory using a $10 \mathrm{~mm}$ snare, resulting in an immediate reduction of the mean systemic venous pressure from 23 to $19 \mathrm{~mm} \mathrm{Hg}$ and the oxygen saturations from $93 \%$ to $78 \%$. He made a full recovery, and no further attempts were made to close the fenestration.

Patients who developed heart failure after fenestration closure more often received digoxin ( $75 \%$ vs. $18 \%, p=0.003)$ and sildenafil $(87.5 \%$ vs. 
$36 \%, p=0.015)$ prior to the procedure (Table IV). They were also more likely to have systolic impairment of the systemic ventricle $(75 \%$ vs. $2.5 \%$, $p=0.01)$ and at catheterization had significantly higher systemic venous pressures before $(15.6 \pm 2.0 \mathrm{~mm}$ Hg vs. $13.9 \pm 2.1 \mathrm{~mm} \mathrm{Hg}, p=0.039)$ and after (17.2 $\pm 1.8 \mathrm{~mm} \mathrm{Hg}$ vs. $15.2 \pm 2.2 \mathrm{~mm} \mathrm{Hg}$, $p=0.02)$ fenestration closure. They also had lower oxygen saturations ( $92.7 \pm 3.8 \%$ vs. $94.6 \pm 1.7 \%$, $p=0.035)$ on the day after fenestration closure.

\section{Follow-up}

All 47 patients attended scheduled outpatient visits. At the latest median follow-up of 19.6 months (range: 8-33.5 months), there were no deaths or further interventions. Figure 2 illus- trates finger-tip arterial oxygen saturations before and after fenestration closure and during follow-up visits. Color Doppler TTE showed residual flow across the device in 10 (22\%), 5 (11\%) and $4(9 \%)$ patients at 1 and 6 months and the latest follow-up, respectively (Figure 3 ).

At the latest follow-up, the mean oxygen saturation in room air was $93.7 \pm 3.4 \%$ (excluding the patient who had the fenestration reopened). Trivial residual color flow was seen in 4 patients, whose oxygen saturations were significantly lower than in the patients with no detectable residual fenestration flow $(88.5 \pm 3.9 \%$ vs. 94.5 $\pm 2 \%, p<0.05$ ). There was no evidence of clot formation in any patients following fenestration closure.

Table IV. Comparison between patients who developed heart failure symptoms early after fenestration closure and those with uneventful post-intervention course

\begin{tabular}{|c|c|c|c|}
\hline Parameter & $\mathrm{HF}(N=8)$ & No HF $(N=39)$ & $P$-value \\
\hline Age at fenestration closure [years] & $6.3 \pm 0.96$ & $6.2 \pm 1.7$ & 0.844 \\
\hline Time after TCPC [months] & $12.7 \pm 9.3$ & $14.3 \pm 9.1$ & 0.660 \\
\hline Weight [kg] & $18.4 \pm 2.6$ & $19.7 \pm 4.5$ & 0.433 \\
\hline \multicolumn{4}{|l|}{ Medication: } \\
\hline ACEI & $7(87.5 \%)$ & $20(51 \%)$ & 0.114 \\
\hline Diuretics & $7(87.5 \%)$ & $29(74 \%)$ & 0.659 \\
\hline Digoxin & $6(75 \%)$ & $7(18 \%)$ & 0.003 \\
\hline Sildenafil & $7(87.5 \%)$ & $14(36 \%)$ & 0.015 \\
\hline \multicolumn{4}{|l|}{ Fenestration: } \\
\hline Size on angiography [mm] & $5.6 \pm 1.1$ & $5.0 \pm 0.8$ & 0.055 \\
\hline Gradient on TTE [mm Hg] & $10.1 \pm 2.2$ & $10.1 \pm 2.0$ & 0.972 \\
\hline AV valve regurgitation (\%) & $6(75 \%)$ & $35(89.7 \%)$ & 0.403 \\
\hline SV function impairment (\%) & $6(75 \%)$ & $1(2.5 \%)$ & 0.001 \\
\hline \multicolumn{4}{|l|}{ Sat $\mathrm{O}_{2}(\%)$ : } \\
\hline Before closure in room air & $76.0 \pm 5.8$ & $77.3 \pm 5.9$ & 0.562 \\
\hline Before closure* & $83.2 \pm 6.7$ & $85.1 \pm 6.0$ & 0.431 \\
\hline After closure* & $98.1 \pm 1.9$ & $97.6 \pm 3.2$ & 0.629 \\
\hline After closure in room air & $92.7 \pm 3.8$ & $94.6 \pm 1.7$ & 0.035 \\
\hline \multicolumn{4}{|l|}{ Systemic venous pressure [mm $\mathrm{Hg}]$ : } \\
\hline Before closure & $15.6 \pm 2.0$ & $13.9 \pm 2.1$ & 0.039 \\
\hline After closure & $17.2 \pm 1.8$ & $15.2 \pm 2.2$ & 0.020 \\
\hline \multicolumn{4}{|l|}{ Residual flow (\%): } \\
\hline On angiography & $7(87.5 \%)$ & $36(92.3 \%)$ & 0.652 \\
\hline On TTE & $2(25 \%)$ & $16(41 \%)$ & 0.698 \\
\hline
\end{tabular}

HF - heart failure, *mechanical ventilation with $40 \%$ oxygen, TCPC - total cavo-pulmonary connection, ACEI - angiotensin converting enzyme inhibitor, TTE - transthoracic echocardiography, AV - atrio-ventricular, SV - single ventricle, Sat - saturation. 


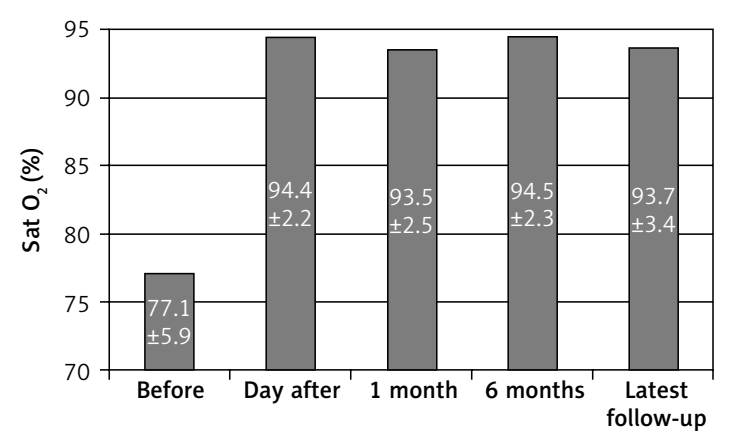

Figure 2. Relation between fingertip arterial oxygen saturations $\left(\mathrm{Sat} \mathrm{O}_{2}\right.$ ) and time after fenestration closure

There was no deterioration of ventricular function or increase in atrio-ventricular (AV) valve regurgitation in any patient at the latest follow-up, compared with pre-closure assessments.

\section{Discussion}

Over the last 15 years, a variety of devices have been used in our unit for closing fenestrations. These included double disc devices such as Starflex, Cardia, Amplatzer Cribriform and Amplatzer Septal Occluder (ASO) $[29,30]$. In patients with coexisting tunnel stenosis, large or multiple communications or unfavorable localization of the fenestration for a disc device, we have used covered stents, resulting in simultaneous exclusion of the fenestration and relief of obstruction. Large delivery sheaths, the lack of a retrieval option, and limited options to re-fenestrate, if problems arise, are the potential major drawbacks of covered stents.

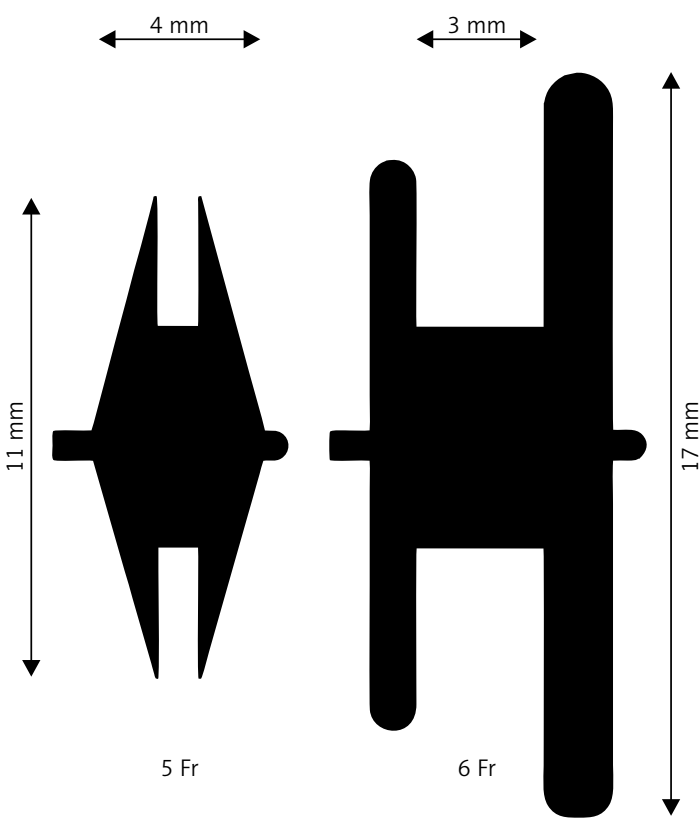

Figure 4. Diagram presenting a $1: 1$ comparison of the most commonly used device in this study, 5/4 mm Amplatzer Duct Occluder II, and corresponding $5 \mathrm{~mm}$ Amplatzer Septal Occluder

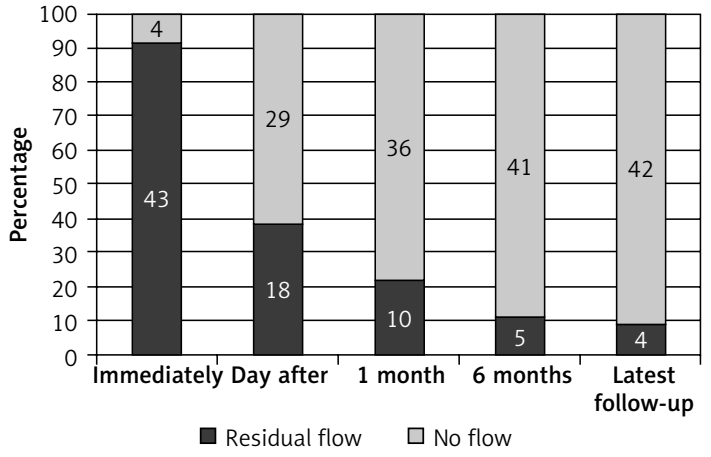

Figure 3. Relation between persistence of residual flow and time after fenestration closure

The ADO II shares some design features with the ASO. However, due to the thinner nitinol wires and a lack of fabric patches within the discs, the ADO II has a smaller profile and is much softer. Figure 4 presents a comparison between the most commonly used device in our population, $5 / 4 \mathrm{~mm}$ ADO II, and the corresponding $5 \mathrm{~mm}$ ASO. Fenestration occlusion with the ADO II results in less metal material in the atrium and allows the use of this device in those patients in whom the curved shape of the tunnel wall may prevent correct alignment of the discs using devices such as the ASO. The largest ADO II has a $6 \mathrm{~mm}$ waist with $12 \mathrm{~mm}$ diameter discs. This limits the use of ADO II to communications measuring approximately $6 \mathrm{~mm}$. Larger fenestrations are rarely encountered, meaning that most patients have fenestrations which can be closed with the ADO II.

We have described easy removal of this device following heart failure symptoms relatively acutely after fenestration closure. In case of later onset of failing Fontan symptoms after device closure, a new fenestration may be established with transcatheter techniques [31-33]. The smaller disc of the ADO II may maximize the space available to perform a puncture and construct a new communication. Should the need to perform electrophysiology study or intervention arise in the future, the smaller occluder profile may also be beneficial.

Various modalities have been used to measure the communication including transesophageal echocardiography, intra-cardiac ultrasound, balloon sizing or 3DRA $[8,9,34-36]$. We rely on angiography, and recently we have moved to 3DRA to visualize the TCPC and measure the size of the fenestration. Figure 5 shows an example of post-processing of a $3 \mathrm{D}$ reconstructed image in a TCPC patient before fenestration closure. The softness of the ADO II makes accurate fenestration sizing very important. An oversized device is likely to elongate within the fenestration, resulting in poor apposition of the discs of the device to the wall of the atrium and the systemic venous pathway. This could lead to device embolization, 


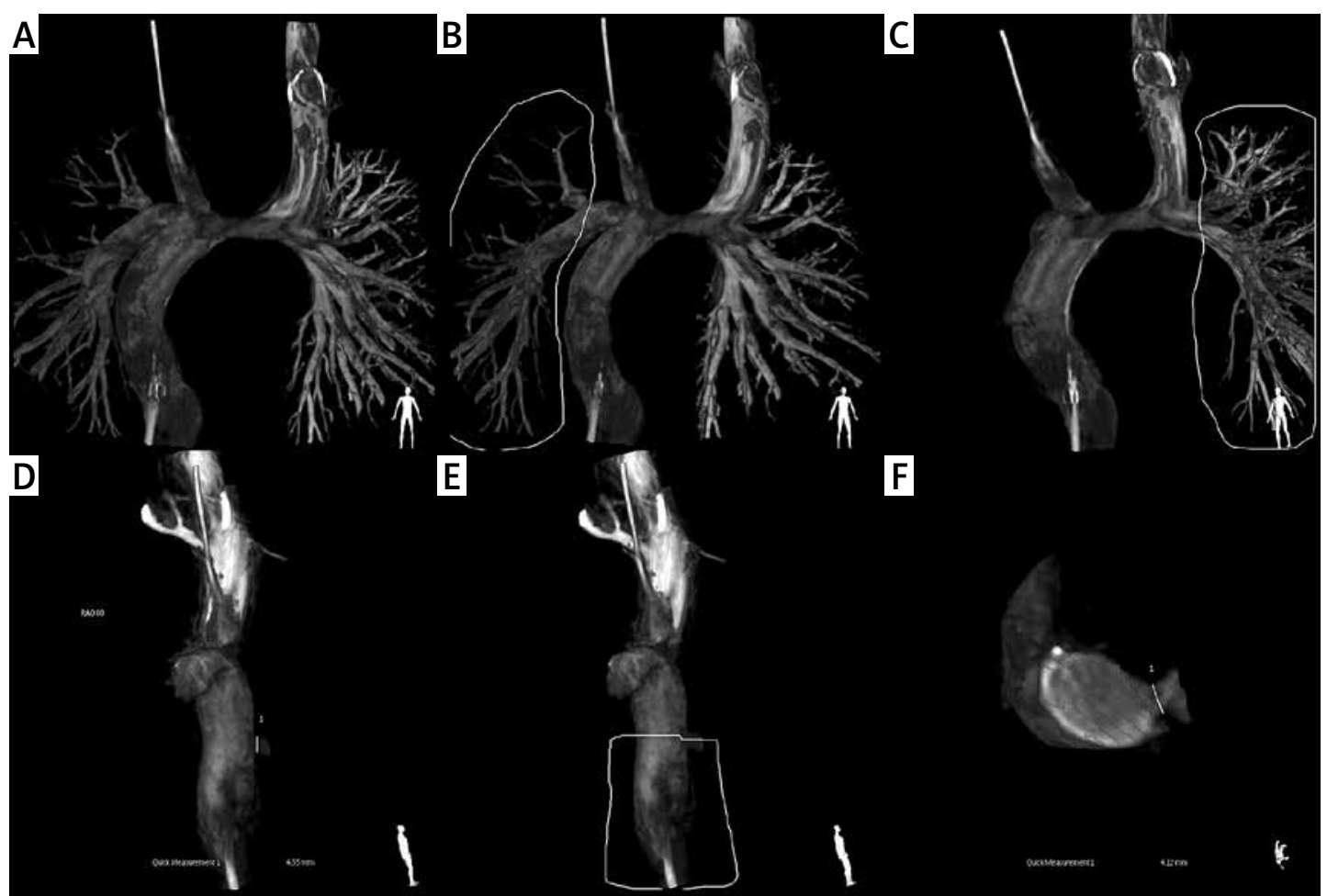

Figure 5. Volume-rendered 3D reconstruction of rotational angiography images in fenestrated TCPC patient. A - Multisite contrast injection including IVC, ISVC and rSVC was used to obtain complete visualization of the Fontan pathway in one RA run. B, C - Cutting out of the right and left pulmonary artery respectively. D - Measurement of the size of fenestration in sagittal plane corresponding to RAO projection. E - Cutting out of part of the extracardiac tunnel. $\mathbf{F}$ - Measurement of the fenestration in transverse plane, which is not achievable in standard angiography

TCPC - total cavo-pulmonary connection, IVC - inferior vena cava, ISVC - left-sided superior vena cava, rSVC - right-sided superior vena cava, RAO - right anterior oblique.

persistent residual flow or turbulent flow and clot formation. With an undersized device, the waist will not completely fill the communication, resulting in fewer Nitinol cross-sections than required to achieve permanent occlusion.

Those patients who developed early heart failure following device closure had evidence of sub-optimal hemodynamics, in terms of prescribed medications and systolic ventricular function. They also had significantly higher systemic venous pressures both before and after fenestration closure. Despite these factors, we proceeded to close fenestrations in this group, with the aim of increasing oxygen saturations and the exercise capacity, with the potential of risking destabilization and a failing Fontan circulation. Only one patient required removal of the occlusion device, which was performed percutaneously without complications. The rest of the patients were discharged after optimization of their medications and did not develop ascites, edema or other symptoms subsequently.

High rates of complete fenestration occlusion have been reported immediately after implantation of double disc devices with fabric patches within them [8, 13-16]. The ADO II has no patch; hence almost all patients had residual flow in the post-deployment angiography. The low velocity flow across the fenestration, coupled with effectively 6 layers of nitinol, results in a high chance of eventual complete occlusion. In our population, less than half of those with residual flow on immediate angiography had persistent leak on the next day, and further reductions in residual flow were observed throughout follow-up. At the latest follow-up, 4 patients had trivial residual flow through the device.

Limitations of this study are consistent with the retrospective nature of the study and a relatively short follow-up. The described population consisted of selected higher risk patients at the time of the TCPC and only those with clinically significant fenestrations. Exercise capacity tests before and after the intervention were available only in a few patients; therefore no formal assessment of patients' clinical improvement was attempted in this study. Further follow-up is required to make firm assertions regarding improvement of exercise capacity and more general quality of life.

In conclusion, we have evaluated the technique and medium-term results of TCPC fenestration closure with the ADO II device in 47 
consecutive patients. The majority of patients had systemic right ventricles, with hypoplastic left heart syndrome (HLHS) being the most frequent diagnosis. This is the largest study of a single device type for extra-cardiac tunnel fenestration occlusion. The ADO II can be safely and effectively used to close fenestrations in extra-cardiac type Fontan completions. Many of the design features of the device aimed at tubular PDA anatomy are applicable and potentially beneficial in this population. Easy recapture and retrieval of the device is also beneficial when dealing with patients who react unfavorably to fenestration occlusion.

\section{Acknowledgments}

This project was supported with research grant (NN 407255040) by the National Science Center, Poland.

\section{Conflict of interest}

The authors declare no conflict of interest.

\section{References}

1. Bridges ND, Lock JE, Castaneda AR. Baffle fenestration with subsequent transcatheter closure. Modification of the Fontan operation for patients at increased risk. Circulation 1990; 82: 1681-9.

2. Laks H, Pearl JM, Haas GS, et al. Partial Fontan: advantages of an adjustable interatrial communication. Ann Thorac Surg 1991; 52: 1084-95.

3. Mavroudis C, Zales VR, Backer CL, Muster AJ, Latson LA. Fenestrated Fontan with delayed catheter closure. Effects of volume loading and baffle fenestration on cardiac index and oxygen delivery. Circulation 1992; 86: 1185-92.

4. Lemler MS, Scott WA, Leonard SR, Stromberg D, Ramaciotti $C$. Fenestration improves clinical outcome of the Fontan procedure: a prospective, randomized study. Circulation 2002; 105: 207-12.

5. Hijazi ZM, Fahey JT, Kleinman CS, Kopf GS, Hellenbrand WE. Hemodynamic evaluation before and after closure of fenestrated Fontan. An acute study of changes in oxygen delivery. Circulation 1992; 86: 196-202.

6. Fu S, Valeske K, Akinturk H, Schranz D. Fontan extracardiac tunnel connection: fenestration or not? Chin Med J (Engl) 2009; 122: 2335-8.

7. Wilson DG, Wisheart JD, Stuart AG. Systemic thromboembolism leading to myocardial infarction and stroke after fenestrated total cavopulmonary connection. $\mathrm{Br}$ Heart J 1995; 73: 483-5.

8. Tofeig M, Walsh KP, Chan C, Ladusans E, Gladman G, Arnold R. Occlusion of Fontan fenestrations using the Amplatzer septal occluder. Heart 1998; 79: 368-70.

9. Momenah TS, Eltayb H, Oakley RE, Qethamy HA, Faraidi YA. Effects of transcatheter closure of Fontan fenestration on exercise tolerance. Pediatr Cardiol 2008; 29: 585-8.

10. Goff DA, Blume ED, Gauvreau K, Mayer JE, Lock JE, Jenkins KJ. Clinical outcome of fenestrated Fontan patients after closure: the first 10 years. Circulation 2000; 102: 2094-9.
11. Pearl JM, Laks H, Barthell S, Drinkwater DC Jr, Capouya ER, Chang PA. Spontaneous closure of fenestrations in an interatrial Gore-Tex patch: application to the Fontan procedure. Ann Thorac Surg 1994; 57: 611-4.

12. Travison TG, McCrindle BW, Mahony L, et al. Late status of Fontan patients with persistent surgical fenestration. J Am Coll Cardiol 2011; 57: 2437-43.

13. Pihkala J, Yazaki S, Mehta R, Lee KJ, Chaturvedi R, McCrindle BW. Feasibility and clinical impact of transcatheter closure of interatrial communications after a fenestrated Fontan procedure: medium-term outcomes. Catheter Cardiovasc Interv 2007; 69: 1007-14.

14. Sommer RJ, Recto M, Golinko RJ, Griepp RB. Transcatheter coil occlusion of surgical fenestration after Fontan operation. Circulation 1996; 94: 249-52.

15. Gamillscheg A, Beitzke A, Stein JI, Rupitz M, Zobel G, Rigler B. Transcatheter coil occlusion of residual intraatrial communications after Fontan procedure. Heart 1998; 80: 49-53.

16. Rueda F, Squitieri C, Ballerini L. Closure of the Fenestration in the extracardiac Fontan with the Amplatzer duct occluder device. Catheter Cardiovasc Interv 2001; 54: 88-92.

17. Crowley DI, Donnelly JP. Use of Amplatzer occlusion devices to occlude Fontan baffle leaks during fenestration closure procedures. Catheter Cardiovasc Interv 2008; 71: 244-9.

18. Ebeid MR, Mehta I, Gaymes CH. Closure of external tunnel Fontan fenestration: a novel use of the Amplatzer vascular plug. Pediatr Cardiol 2009; 30: 15-9.

19. Malekzadeh-Milani S, Ladouceur M, Bajolle F, Bonnet D, Boudjemline Y. Closure of Fontan fenestration with the use of covered stents: short- and mid-term results in a cohort of 50 patients. Cardiol Young 2015; 25: 868-73.

20. Forsey J, Kenny D, Morgan G, et al. Early clinical experience with the new Amplatzer Ductal Occluder II for closure of the persistent arterial duct. Catheter Cardiovasc Interv 2009; 74: 615-23.

21. Dua J, Chessa M, Piazza L, et al. Initial experience with the new Amplatzer Duct Occluder II. J Invasive Cardiol 2009; 21: 401-5.

22. Kang SL, Morgan G, Forsey J, Tometzki A, Martin R. Longterm clinical experience with Amplatzer Ductal Occluder II for closure of the persistent arterial duct in children. Catheter Cardiovasc Interv 2014; 83: 1102-8.

23. Kanaan M, Ewert P, Berger F, Assa S, Schubert S. Follow-up of patients with interventional closure of ventricular septal defects with Amplatzer Duct Occluder II. Pediatr Cardiol 2015; 36: 379-85.

24. Mahimarangaiah J, Subramanian A, Kikkeri Hemannasetty S, Chandra S. Transcatheter closure of perimembranous ventricular septal defects with ductal occluders. Cardiol Young 2015; 25: 918-26.

25. Zhao T, Lu M, So A, et al. Transcatheter closure of coronary artery fistulae: initial human experience with the Amplatzer Duct Occluder II. J Interv Cardiol 2013; 26: 359-65.

26. Kenny D, Walsh KP. Transcatheter occlusion of a classical BT shunt with the Amplatzer Duct Occluder II. Catheter Cardiovasc Interv 2008; 72: 841-3.

27. Kursaklioglu H, Barcin C, Iyisoy A, Baysan O, Celik T, Kose $\mathrm{S}$. Percutaneous closure of mitral paravalvular leak via retrograde approach: with use of the Amplatzer duct occluder II and without a wire loop. Tex Heart Inst J 2010; 37: 461-4.

28. Noonan PM, Desai T, Degiovanni JV. Closure of an aortopulmonary window using the Amplatzer Duct Occluder II. Pediatr Cardiol 2013; 34: 712-4. 
29. Moszura T, Mazurek-Kula A, Dryzek P, et al. Interventions complementing surgery as part of multistage treatment for hypoplastic left heart syndrome: one center's experience. Pediatr Cardiol 2009; 30: 106-13.

30. Moszura T, Dryzek P, Goreczny S, et al. A 10-year single-centre experience in percutaneous interventions for multi-stage treatment of hypoplastic left heart syndrome. Cardiol Young 2014; 24: 54-63.

31. Michel-Behnke I, Luedemann M, Bauer J, Hagel KJ, Akintuerk H, Schranz D. Fenestration in extracardiac conduits in children after modified Fontan operation by implantation of stent grafts. Pediatr Cardiol 2005; 26: 93-96.

32. Gewillig M, Boshoff D, Delhaas T. Late fenestration of the extracardiac conduit in a Fontan circuit by sequential stent flaring. Catheter Cardiovasc Interv 2006; 67: 298-301.

33. Vyas H, Driscoll DJ, Cabalka AK, Cetta F, Hagler DJ. Results of transcatheter Fontan fenestration to treat protein losing enteropathy. Catheter Cardiovasc Interv 2007; 69: 584-9.

34. Giannakoulas G, Thanopoulos V. Three-dimensional transesophageal echocardiography for guiding percutaneous Fontan fenestration closure. Echocardiography 2014; 31: E230-1.

35. Al-Hay AA, Shaban LA, Al-Qbandi MA, Alanbaei M. Occlusion of Fontan fenestrations using Amplatzer septal occluder. Int J Cardiovasc Imaging 2011; 27: 483-90.

36. Hill J, Bellotti C, Golden A. Three-dimensional rotational angiography during percutaneous device closure of Fontan fenestration. World J Pediatr Congenit Heart Surg 2013; 4: 324-5. 